\title{
A 38-year-old man presenting with a $>1$-month history of increased sensitivity to touch in the right index finger, thumb and middle finger with a positive Tinel's sign over the median nerve
}

\author{
Georgiana Zamfir ${ }^{1} \cdot$ Halimah Chattun ${ }^{2} \cdot$ Zaina Alam $^{3} \cdot$ Jan Coebergh $^{4} \cdot$ Asif Saifuddin $^{5}$ \\ Received: 17 December 2020 / Revised: 30 March 2021 / Accepted: 8 April 2021 / Published online: 23 April 2021 \\ (C) Crown 2021
}

\section{Answer}

Thrombosed persistent median artery resulting in compression of a bifid median nerve.

\section{Discussion}

\section{Imaging findings}

Figure $1 \mathrm{a}$ and $1 \mathrm{~b}$ demonstrate a markedly distended vessel within the carpal tunnel with loss of normal flow-void consistent with thrombosis. More proximally in the distal forearm, there are 3 small calibre vessels lying immediately adjacent to a normal-sized median nerve (MN), these representing the persistent median artery (PMA) and venae comitantes (Fig. 1c). Figure 1d shows the thrombosed vessel lying between and compressing the 2 nerve bundles of a bifid MN and bowing of the flexor retinaculum consistent with raised intracompartmental pressure. Doppler US showed a normal arterial wave pattern confirming that the vessel is a PMA (Fig. 2a),

The case presentation can be found at https://doi.org/10.1007/s00256021-03785-w while within the carpal tunnel the distended PMA is filled with echogenic thrombus (Fig. 2b).

\section{Disease definition and its significance}

The PMA is an accessory artery that arises from the ulnar artery in the proximal forearm and courses adjacent to the MN. The median artery, which provides major intraembryonic blood supply to the forearm and hand, normally regresses by the 8 th week of gestation. The PMA is unilateral in approximately $70 \%$ of cases and commonly associated with an anomalous median nerve which is frequently bifid. Cadaveric studies focusing on the anomalous PMA have found that prevalence varies from 0.6 to $30 \%$. Bifid MN prevalence is also variable and ranges from 2 to $26 \%$ per wrist. The bifid $\mathrm{MN}$ anomaly has been reported to have an incidence of $0.8-2.8 \%$ in patients with CTS, and in most cases, it has been reported with a concomitant PMA [1-4]. More recent studies focused on depicting these findings using randomly selected patients who underwent MR imaging have been carried out. It has been proven that there was a high prevalence of bifid

\author{
Georgiana Zamfir \\ g.zamfir@nhs.net \\ Halimah Chattun \\ halimah.chattun3@nhs.net \\ Zaina Alam \\ zainaalam8@gmail.com \\ Jan Coebergh \\ jan.coebergh@nhs.net \\ Asif Saifuddin \\ asif.saifuddin@nhs.net
}

1 ST6 Radiology Registrar, Department of Radiology, Ashford and St Peter's Hospitals NHS Foundation Trust, Guildford Road, Chertsey, Surrey KT16 0PZ, UK

2 ST4 Radiology Registrar, Department of Radiology, Ashford and St Peter's Hospitals NHS Foundation Trust, Guildford Road, Chertsey, Surrey KT16 0PZ, UK

3 University College London Medical School, 74 Huntley Street, London WC1E 6BT, UK

4 Department of Neurology, St George's Hospital, Blackshaw Road, Tooting, London SW17 0QT, UK

5 Department of Radiology, Royal National Orthopaedic Hospital, Brockley Hill, Stanmore HA7 4LP, UK 


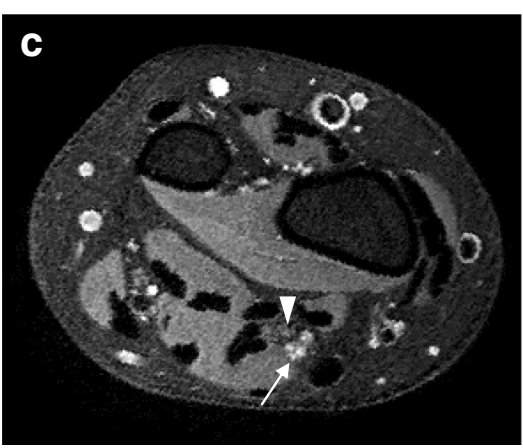

Fig. 1 c Axial fat-suppressed PDW FSE MR image of the right distal forearm shows the persistent median artery and venae comitantes (arrow) adjacent to the median nerve (arrowhead) just proximal to the carpus. d

median nerve (19\%) and PMA (11\%) within the carpal tunnel regardless of gender or age. The PMA was more frequently identified on the left side, unlike our case report [5].

\section{Case contextualisation and patient's management/ outcome}

The current patient presented with symptoms in the median nerve distribution and the imaging appearances are classical for a thrombosed PMA with associated bifid median nerve. Anticoagulation therapy has been instituted and the thrombosed PMA will be monitored with repeat Doppler US. If symptoms persist, the patient will be considered for surgical decompression.

\section{Differential diagnoses}

The commonest differential diagnosis is idiopathic carpal tunnel syndrome (CTS). On sonography and MRI, there is enlargement of the median nerve proximal to the flexor retinaculum, distal flattening of the nerve and palmar bowing of the flexor retinaculum. Other differential diagnoses include $\mathrm{MN}$ compression at the elbow, cervical radiculopathy (C6, C7), flexor carpi radialis tenosynovitis, brachial plexopathy,

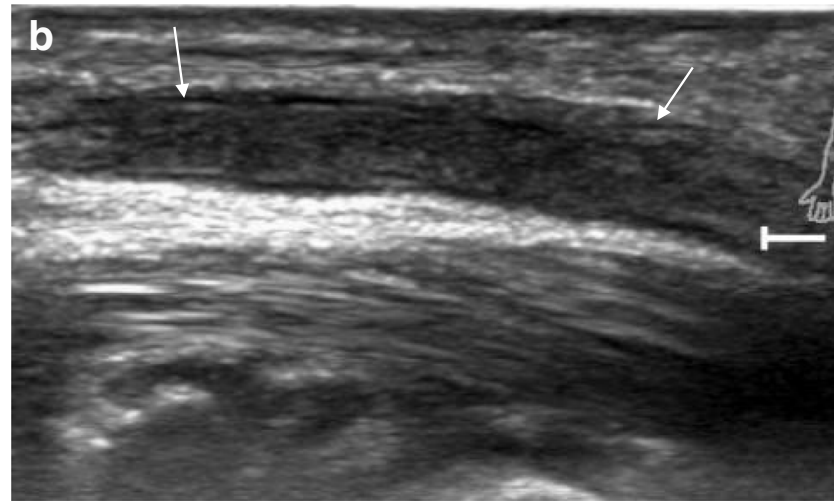

Fig. 2 b Longitudinal US at the level of the carpal tunnel showing the enlarged thrombosed persistent median artery (arrows)

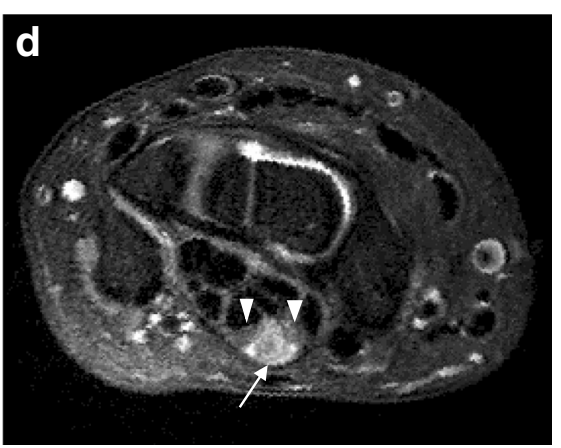

Axial fat-suppressed PDW FSE MR image of the right wrist shows the enlarged thrombosed persistent median artery (arrow) between a bifid median nerve (arrowheads) within the carpal tunnel

thoracic outlet syndrome and 1st carpo-metacarpal joint arthritis [6].

\section{Take home message}

A PMA and bifid median nerve should always be sought when assessing the carpal tunnel on both MRI and ultrasound. Whilst thrombosis of a PMA is very rare, these normal variants are important findings to document both in relation to percutaneous carpal tunnel steroid injections and surgical decompression. Treatment of a thrombosed PMA is initially conservative with anticoagulation therapy [7], but surgical decompression can be considered if symptoms persist [8].

Asif Saifuddin: Conceptualisation, review of draft manuscript and proof read final manuscript.

Author contribution Georgiana Zamfir: conceptualization, principal investigator, literature review, writing of draft and final manuscripts, proof read final manuscript.

Halimah Chattun: literature review, writing of draft manuscript, proof read final manuscript.

Zaina Alam: literature review, writing of draft manuscripts.

Jan Coebergh: proof read final manuscript.

\section{Declarations}

All authors reviewed and are happy with the final manuscript version submitted for review.

Conflict of interest The authors declare no competing interests.

\section{References}

1. Singla RK, Kaur N, Dhiraj GS. Prevalence of the persistant median artery. J Clin Diagn Res. 2012;6:1454-7.

2. Akgun AS, Ertan G, Ulus S. Acute carpal tunnel syndrome caused by thrombosed persistent median artery associated with bifurcated median nerve in a pregnant woman. BMJ Case Rep. 2017;2017: bcr2017221446. 
3. Lisanti M, Rosati M, Pardi A. Persistent median artery in carpal tunnel syndrome. Acta Orthop Belg. 1995;61:315-8.

4. Aulicino PL, Klavans SM, DuPey TE. Digital ischemia secondary to thrombosis of persistent median artery. Digital ischemia secondary to thrombosis of persistent median artery. J Hand Surg. 1984;9:820-3.

5. Pierre-Jerome C, Smitson RD, Shah RK, et al. MRI of the median nerve and median artery in the carpal tunnel: prevalence of their anatomical variations and clinical significance. Surg Radiol Anat. 2010;32:315-22.

6. Miller TT, Reinus WR. Nerve entrapment syndromes of the elbow, forearm, and wrist. AJR Am J Roentgenol. 2010;195(3):585-94.
7. Srivastava A, Sharma P, Pillay S. Persistent median artery thrombosis: a rare cause of carpal tunnel syndrome. Australas J Ultrasound Med. 2015;18:82-5.

8. Bartels DW, Shin AY. Surgical excision of a thrombosed persistent median artery causing carpal tunnel-like symptoms: a case report. JBJS Case Connect. 2020 Jul-Sep;10(3):e2000139.

Publisher's note Springer Nature remains neutral with regard to jurisdictional claims in published maps and institutional affiliations. 